\title{
Peri-operative approach to esophagectomy: a narrative review from the anesthesiological standpoint
}

\author{
Cristian Deana $^{1}$, Luigi Vetrugno ${ }^{1,2} \wedge$, Elena Bignami $^{3}$, Flavio Bassi $^{1}$ \\ ${ }^{1}$ Department of Anesthesia and Intensive Care, ASUFC-Academic Hospital of Udine, Udine, Italy; ${ }^{2}$ Department of Medical Area, University of \\ Udine, Udine, Italy; ${ }^{3}$ Anesthesiology, Critical Care and Pain Medicine Division, Department of Medicine and Surgery, University of Parma, Parma, \\ Italy \\ Contributions: (I) Conception and design: All authors; (II) Administrative support: All authors; (III) Provision of study materials or patients: All \\ authors; (IV) Collection and assembly of data: C Deana, L Vetrugno; (V) Data analysis and interpretation: All authors; (VI) Manuscript writing: All \\ authors; (VII) Final approval of manuscript: All authors. \\ Correspondence to: Cristian Deana, MD. Anesthesia and Intensive Care 1, Department of Anesthesia and Intensive Care, ASUFC-Academic Hospital \\ of Udine, Piazzale S. Maria della Misericordia 15, 33100 Udine, Italy. Email: Cristian.deana@asufc.sanita.fvg.it.
}

Objective: This review summarizes the peri-operative anesthesiological approaches to esophagectomy considering the best up-to-date, evidence-based medicine, discussed from the anesthesiologist's standpoint.

Background: Esophagectomy is the only curative therapy for esophageal cancer. Despite the many advancements made in the surgical treatment of this tumour, esophagectomy still carries a morbidity rate reaching $60 \%$. Patients undergoing esophagectomy should be referred to high volume centres where they can receive a multidisciplinary approach to treatment, associated with better outcomes. The anesthesiologist is the key figure who should guide the peri-operative phase, from diagnosis through to post-surgery rehabilitation. We performed an updated narrative review devoted to the study of anesthesia management for esophagectomy in cancer patients.

Methods: We searched MEDLINE, Scopus and Google Scholar databases from inception to May 2021. We used the following terms: "esophagectomy", "esophagectomy AND pre-operative evaluation", "esophagectomy AND protective lung ventilation", "esophagectomy AND hemodynamic monitoring” and "esophagectomy AND analgesia". We considered only articles with abstract written in English and available to the reader. We excluded single case-reports.

Conclusions: Pre-operative anesthesiological evaluation is mandatory in order to stratify and optimize any medical condition. During surgery, protective ventilation and judicious fluid management are the cornerstones of intraoperative "protective anesthesia". Post-operative care should be provided by an intensive care unit or high-dependency unit depending on the patient's condition, the type of surgery endured and the availability of local resources. The provision of adequate post-operative analgesia favours early mobilization and rapid recovery. Anesthesiologist has an important role during the peri-operative care for esophagectomy. However, there are still some topics that need to be further studied to improve the outcome of these patients.

Keywords: Esophagectomy; protective lung ventilation; perioperative cardiac risk assessment; perioperative fluid management; hemodynamic monitoring

Submitted Jun 07, 2021. Accepted for publication Aug 19, 2021.

doi: $10.21037 /$ jtd-21-940

View this article at: https://dx.doi.org/10.21037/jtd-21-940

^ ORCID: Cristian Deana, 0000-0002-1626-3177; Luigi Vetrugno, 0000-0003-3745-8368.

(C) Journal of Thoracic Disease. All rights reserved. 


\section{Introduction}

Esophageal cancer is one of the most common solid tumours occurring in humans. Its worldwide incidence is increasing, with one million people expected to be diagnosed by 2040 (Figure 1) $(1,2)$. Squamous cell carcinoma constitutes the most common type of esophageal neoplasm. The second most frequent form is adenocarcinoma, which is rapidly rising in western world, whereas that of the former is declining (3). Sex, age and genetic aspects are the prime non-modifiable risk factors for esophageal cancer. Alcohol and tobacco and a diet poor in fruit and vegetables constitute the prime modifiable risk factors in relation to esophageal squamous carcinoma, whereas those related to adenocarcinoma include tobacco, obesity and gastroesophageal reflux disease (4). The mortality rate for this type of tumour is high, with less than $50 \%$ of patients surviving for more than five years after diagnosis (5). A number of reasons may contribute to explaining this low survival rate, including delay in diagnosis, a lack of centralization in high volume centres and inadequate preoperative optimization $(6,7)$.

Esophagectomy remains a complex surgical intervention overwhelmed by a post-operative complication rate of up to $60 \%$, but high volume centres performing more than 20 esophagectomies annually were found to record fewer complications and exhibit better overall survival thanks to higher levels of team expertise $(7,8)$.

A multidisciplinary team is required to take care of these patients from the preoperative setting through to the post-surgery phase $(9,10)$. The anesthesiologist, a leading figure of this team, should be involved in the patient's management from an early time-point as this has been associated with a lower rate of post-operative complications (11). The anesthesiologist should follow the patient throughout the peri-operative period, optimizing the patient's functional status in various settings, including that of esophageal surgery (Figure 2) (12). Considering the central role of the anesthesiologist, this updated narrative review is devoted to the study of anesthesia management for esophagectomy in cancer patients. It explains the importance of comprehensive and complete perioperative care, discussed from the anesthesiologist's point of view.

We present the following article in accordance with the Narrative Review reporting checklist (available at https:// dx.doi.org/10.21037/jtd-21-940).

\section{Methods}

We searched MEDLINE, Scopus and Google Scholar databases from inception to May 2021. We used the following keywords: "esophageal cancer", "esophagectomy", "pre-operative evaluation", "protective lung ventilation", "hemodynamic monitoring", "esophagectomy AND analgesia", "nutritional assessment", "prehabilitation" and "peri-operative cardiac risk". We considered only articles written in English and with abstract available to the reader. We included retrospective, prospective observational or randomized controlled trials, expert's opinion papers and case-series studies. We excluded studies involving non-human patients, preclinical research cases, research protocols, policy statements and single case-reports.

Two authors (CD and $L V$ ) retrieved the full texts of the relevant articles. All other related titles and abstracts were retrieved, and the full versions obtained. The reference lists of the included studies and review articles were manually searched to identify any additional studies relevant to the analysis. Full-text documents were initially assessed for relevance. Articles that did not meet relevance to the review aim were excluded from further analysis.

\section{Discussion}

\section{Types of surgical procedures}

Open esophagectomy (OE) has traditionally been performed with laparotomy and right thoracotomy with intrathoracic anastomosis (while the patient lies in left lateral decubitus) in the Ivor-Lewis operation (13). To overcome problems related to the intrathoracic anastomosis, the three-field McKeown technique with left latero-cervical access (the site of anastomosis) was subsequently developed (14). In this case, the site of anastomosis is situated outside of any previously radiated area to lower the risk of suturing unhealthy tissue and to permit the easier management of any eventual anastomotic leak (15).

To be more precise, the reconstruction route characterizes the leak's management difficulty: the posterior mediastinal anastomotic site of McKeown and Ivor-Lewis is behind the trachea. In contrast, the retrosternal anastomotic site of McKeown locates just under the cervical skin incision. In the first scenario, the site of the anastomotic leakage is more difficult to reach and treat. 
Estimated worldwide number of new cases of esophageal cancer from 2020 to 2040

\section{0 \\ itipitipi \\ ii}

$604 \mathrm{~K}$

\section{ipitipitipi \\ ipipipioin \\ $988 \mathrm{~K}$}

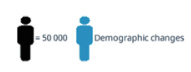

Data source: GLOBOCAN 2020 http://gco.iarc.fir/today

Figure 1 The projected trend for esophageal cancer from 2020 to 2040. Nearly 1 million new diagnoses of esophageal cancer are expected by 2040 .

Peri-operative care for esophagectomy

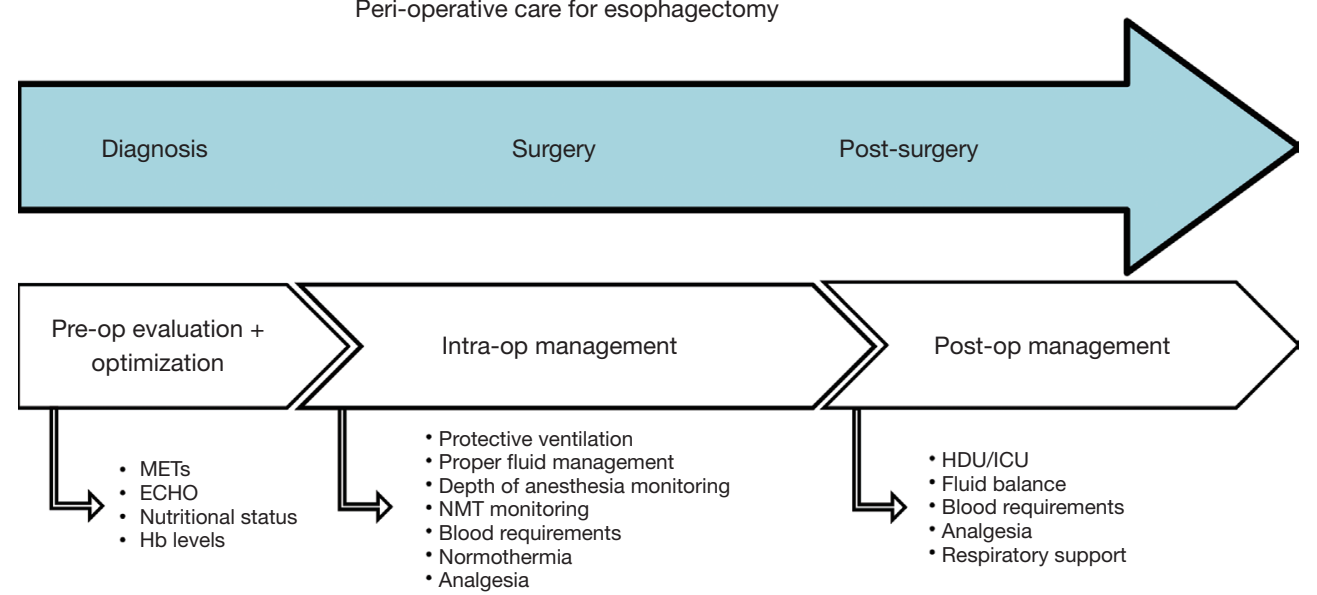

Figure 2 Peri-operative care for esophagectomy. The anesthesiologist is required to follow the patient throughout the entire peri-operative phase: during pre-operative evaluation, the patient is referred to the anesthesiologist for the optimization of their medical conditions; whereas intra-operatively their task is to provide the best evidence-based "protective anesthesia" in order to maximize post-operative recovery. After surgery, rapid return to normal life should be pursued. METs, metabolic equivalents; ECHO, echocardiography; NMT, neuromuscular transmission; HDU, high dependency unit.

Transhiatal esophagectomy (THE) does not involve thoracotomy; however, the blunt dissection of the esophagus makes extensive lymphadenectomy extremely difficult. As a result, the potential advantages gained by THE, being fewer morbidities and a lower risk of mortality, need to be weighed against the possibility of compromising the cancer outcome (16).

The need to improve post-operative outcomes despite the availability of more sophisticated surgical instruments has been addressed by increasing surgeon expertise. This led to the use of less invasive approaches, such as minimally invasive esophagectomy (MIE), which could be used for both the Ivor-Lewis and McKeown procedures. No single standardized technique exists since the preferred patient position adopted for the same surgical procedure may vary between different centres (17). However, MIE has led to a reduction in post-operative complications and improved functional recovery without compromising oncological outcome (18).

Technical limitations of MIE, such as the twodimensional view and restricted range of movement, have been resolved thanks to the development of robotic assisted MIE (RAMIE). Indeed, recent evidence concluded it to be a feasible and safe technique, and with better shortterm outcomes compared with MIE. An additional benefit of RAMIE is its lower rate of post-operative pulmonary complications (PPCs) although randomized controlled trials are highly advocated in this regard (19). 
MIE and RAMIE, however, are burdened by longer operative times compared with $\mathrm{OE}$.

MIE has a learning curve of about 75 patients for an individual surgeon; after that, complication's rate is on a stabile level with decreased operative time (20).

Moreover, the anesthetic challenges of MIE, besides prolonged surgery, are the consequent greater difficulties attaining lung isolation and one-lung ventilation (OLV) in the prone position, as well as complications relating to extraperitoneal $\mathrm{CO}_{2}$ (pneumothorax, pneumomediastinum and surgical emphysema).

Consequently, introducing MIE program in a hospital needs intense training and proctoring for both surgeons and anesthesiologists.

In the case of RAMIE, difficult airway access must also be taken into account (21). Finally, the possibility for nerve plexus injury needs to be careful evaluated during the positioning of the patients (22).

\section{Preoperative evaluation}

The 2014 European Society of Cardiology and European Society of Anesthesiology (ESC/ESA) guidelines on noncardiac surgery consider esophagectomy a high-risk surgical procedure with an expected 30-day cardiovascular death or myocardial infarction risk $>5 \%$. However, high volume centers have a lower mortality rate $(23,24)$.

Anesthesiologists, expert in the proposed surgical procedures, should coordinate the patient's preoperative evaluation. The most important objective of the evaluation is to enhance the surgical outcome by identifying potential anesthesia difficulties that could be triggered by existing medical conditions. Other objectives include assessing and quantifying perioperative risk to enable the best perioperative care to be planned, thus maximizing patient safety.

From the prospective of patient safety, the evaluation of patient cardiac risk is fundamental. The cardio-pulmonary exercise test (CPET) is the ideal approach for estimating the cardiac reserve; however, it is not applicable on a large scale being highly time-consuming and given its high costs (25). Functional capacity, evaluated considering the patient's self-reported daily living activities, is considered a valuable alternative (26). It estimates the number of metabolic equivalents (METs) the patient is able to tolerate, where 1 MET is defined as the basal oxygen consumption of a 40-year-old man weighing $70 \mathrm{~kg}$. A multicentre ongoing trial, the MET-REPAIR study, is presently addressing the reliability of MET evaluation (27). Functional capacity in METS is classified in the following manner: excellent (>10 METS), good (7-10 METS), moderate (4-6 METS), poor (<4 METS). The lower the number of METs, the higher the risk of perioperative cardiovascular events (23).

Plasma natriuretic peptide concentration, such as $\mathrm{N}$-terminal pro-brain natriuretic peptide (NT-proBNP) and brain natriuretic peptide (BNP), could serve as adjuncts to cardiovascular risk evaluation. Their high negative predictive value (NPV) is particularly helpful when classifying patients at low risk of complications $(28,29)$.

In the case that non-invasive cardiac examinations indicate a high risk of complications, patients need to be evaluated using CPET. These provide information about the real cardiopulmonary reserve by evaluating maximum oxygen consumption $\left(\mathrm{VO}_{2 \max }\right)$. Patients can subsequently be classified as low (when $\mathrm{VO}_{2 \max }>20 \mathrm{~mL} / \mathrm{kg} / \mathrm{min}$ ), intermediate (if $\mathrm{VO}_{2 \max }$ between 15 to $20 \mathrm{~mL} / \mathrm{kg} / \mathrm{min}$ ) or high risk (when $\mathrm{VO}_{2 \max }<15 \mathrm{~mL} / \mathrm{kg} / \mathrm{min}$ ) (30).

Pre-operative echocardiography (ECHO) is not necessary for all patients undergoing esophagectomy; however, it may be considered as important in high-risk patients after radio-/chemotherapy (31-33).

\section{Pre-operative optimization}

Physiotherapy prior to surgery to enhance cardiopulmonary fitness would seem rational, but studies demonstrating a significant level of efficacy are still ongoing in the setting of esophagectomy (34,35). Patients with esophageal cancer often present weight loss, sarcopenia and cancer cachexia, all of which are risk factors for poor outcome (36). Nutritional status assessment is important, and early dietician referral to optimize fat and protein status is of utmost importance (37). Many screening tools for malnutrition are available. The MUST score is quick and easy to ascertain, and provides clear indications for nutritional intervention. Malnutrition and cancer related cachexia are important to identify as early as possible so that nutritional interventions aimed at improving body mass composition can be implemented promptly $(38,39)$. Hemoglobin levels should be optimized preoperatively to reduce the probability of transfusions, even though a recent randomized controlled clinical trial (RCT) did not demonstrate any benefit from intravenous iron supplementation in anaemic patients $(40,41)$. The impact of pre-habilitation (i.e., strategies to enhance the fitness of the patients undergoing major surgery) on postoperative outcomes after esophagectomy needs to be evaluated by further studies (42). 
Airway management for esophagectomy

\begin{tabular}{|c|c|c|c|}
\hline & SLT & DLT & BB \\
\hline Advantages & $\begin{array}{l}\text { - Easy positioning } \\
\text { - Fast positioning } \\
\text { - Low risk of } \\
\text { malpositioning } \\
\text { - No FOB required } \\
\text { - Easy suctioning }\end{array}$ & $\begin{array}{l}\text { - Adequate OLV } \\
\text { - Low malpositioning risk } \\
\text { - Easy suctioning } \\
\text { - Easy switching from DLV to OLV }\end{array}$ & $\begin{array}{l}\text { - Rapidly available for unexpected } \\
\text { OLV } \\
\text { - Non traumatic } \\
\text { - Fit for small bronchi } \\
\text { - SLT + BB when difficult airway }\end{array}$ \\
\hline Disadvantages & - OLV difficult & $\begin{array}{l}\text { - FOB suggested } \\
\text { - Traumatic } \\
\text { - To be changed if post-op ICU } \\
\text { admission }\end{array}$ & $\begin{array}{l}\text { - FOB required (Skills) } \\
\text { - High malpositioning risk } \\
\text { - Difficult suctioning/collapsing } \\
\text { - Longer positioning } \\
\text { - Unsafe if unexpected hemorrage }\end{array}$ \\
\hline Size & $\begin{array}{l}\text { - M 7.5-8 mm ID } \\
\text { - F 7-7.5 mm ID }\end{array}$ & $\begin{array}{l}\text { - M 39-41 French } \\
\text { - F 35-39 French }\end{array}$ & - 9 French \\
\hline
\end{tabular}

Figure 3 Airway management for esophagectomy. Many different airway management options exist. The best choice will take into consideration the type of surgery performed (OE versus MIE versus RAMIE), the expertise of anesthesiologist and various patient-related factors (such as a predicted difficult airway). When OLV is planned, in the absence of any contraindications, DLT would probably be the preferred choice. SLT, single lumen tube; DLT, double-lumen tubes; BB, bronchial blockers; FOB, fiber optic bronchoscopy; OLV, one-lung ventilation; DLV, double lung ventilation; OE, open esophagectomy; MIE, minimally invasive esophagectomy; RAMIE, robotic assisted minimally invasive esophagectomy.

Home-based pre-habilitation programs could overcome transport-related problems (the most frequent quoted problems) of these patients who often are elderly or in nonoptimal physical conditions. Moreover, adding visits to these patients could be another limiting factor that reduces pre-habilitation program adherence (43).

Recent investigations explored the possibility of telerehabilitation programs delivered through web-based platform staring from 2 to 4 weeks before surgery. The main results highlighted the feasibility, safety and satisfaction of this intervention (44).

\section{Intra-operative management}

\section{Airways}

Airway management is the prime concern of the anesthesiologist (45). Traditional esophagectomy requires OLV. Less invasive procedures, such as MIE and RAMIE, generally involve a thoracoscopic approach. Some centers perform thoracoscopic MIE in the prone position without OLV, which results in more protection to the lung than MIE in the left lateral decubitus with OLV, a known risk factor for lung damage.

To obtain lung separation, the anesthesiologist must identify his preferred device, choosing between doublelumen tubes (DLT), bronchial blockers (BB) or a single lumen tube (SLT). A SLT is the unique choice when OLV is not required (Figure 3). A large multicentre observational study found the DLT to be the preferred device for OLV. It is also associated with fewer complications, such as malpositioning or intraoperative hypoxemia (46). In general, the reported success rates for experts and nonexperts are very similar. The anesthesiologist should be sufficiently skilled in fiber optic bronchoscopy (FOB) to control proper DLT positioning. A DLT with a video camera included at the distal end, allowing continuous visual position monitoring, was recently introduced onto the market (47). BB generally provide less optimal surgical exposure; however, if the patient presents a difficult airway, BB should be considered for OLV after awake intubation with FOB through a SLT (48).

\section{Ventilation}

Intraoperative protective ventilation has become a standard of care in anesthesia. This concept involves controlling the tidal volume (TV) delivered, minimizing the driving pressure, optimizing lung compliance and adopting reasonable levels of positive end-expiratory pressure (PEEP) (49). Protective ventilation reduces so-called "biotrauma" with impending consequences, such as PPCs (50). PPCs after esophagectomy are the most frequent complications (51). Acute respiratory distress syndrome (ARDS) is reported in up to $25 \%$ of patients after esophagectomy requiring OLV, with associated poor outcomes (52).

Esophagectomy is a type of surgery involving both the 


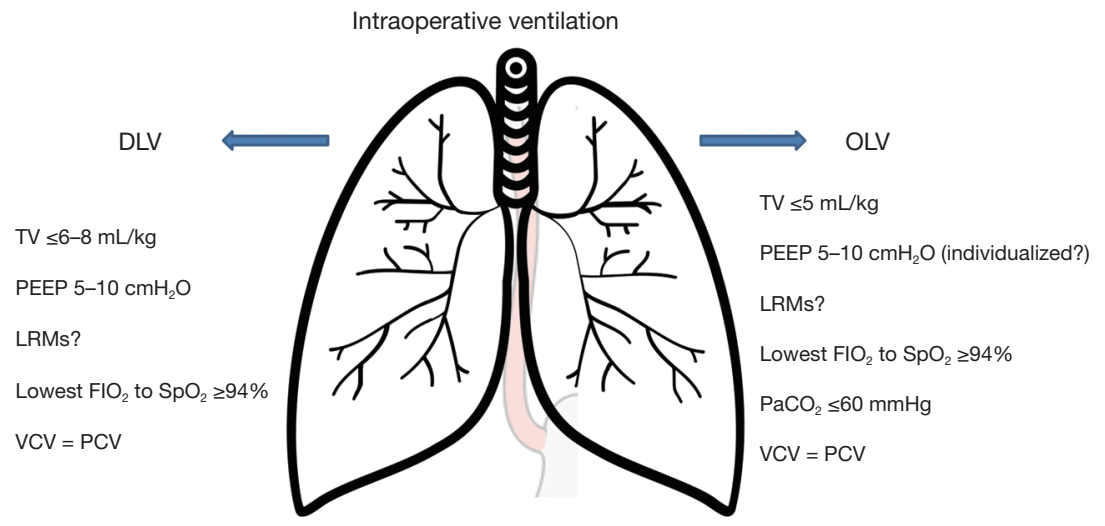

Figure 4 Intra-operative protective ventilation. DLV, double lung ventilation; OLV, one lung ventilation; TV, tidal volume; PEEP, positive end expiratory pressure; LRMs, lung recruiting maneuvers; VCV, volume-controlled ventilation; PCV, pressure-controlled ventilation.

thorax and the abdomen, and thus presents the features of both thoracic and abdominal surgery, especially with regard to ventilation. According to the literature, a TV $\leq 6-8 \mathrm{~mL} / \mathrm{kg}$ of ideal body weight (IBW) is preferable (53-55). If OLV is required, a $T V \leq 5 \mathrm{~mL} / \mathrm{kg}$ of IBW should be used to avoid volutrauma, accepting mild hypercapnia $\left(\mathrm{PaCO}_{2}\right.$ $<60 \mathrm{mmHg}$ ) (56). Moreover, the lowest possible $\mathrm{F}_{\mathrm{I}} \mathrm{O}_{2}$ should be set to obtain a $\mathrm{SpO}_{2}>94 \%$ (Figure 4) (55).

According to the PROVHILO study, higher levels of PEEP in open abdominal surgery do not provide any advantage over the use of lower levels (53). Recent guidelines on intraoperative ventilation suggest $5-10 \mathrm{cmH}_{2} \mathrm{O}$ as the right balance in the majority of surgical procedures (55-58). Individualized PEEP to optimize static lung compliance is a concept of applied physiology. However, larger RCTs are needed $(59,60)$.

Something should also be said regarding MIE in the prone position without OLV. In this case, an excessive PEEP level may impair surgical visualization; thus, close collaboration between the surgeon and anesthesiologist is necessary to obtain the best results for both of these figures.

The evidence available to date is insufficient to support one type of ventilation, pressure-controlled ventilation (PCV) or volume-controlled ventilation (VCV), over the other $(55,61)$. Lung recruiting manoeuvres (LRMs) remain an appealing concept; however, literature data do not lie in support of their routine application, although they should be considered in order to relieve intraoperative hypoxemia, especially during OLV (62). A recent meta-analysis favours total intravenous anesthesia (TIVA) over volatile anesthesia in terms of overall survival, although no statistically significant difference was found in recurrence-free survival (63).
A retrospective study found that TIVA during esophageal cancer surgery was associated with better postoperative survival rates compared with volatile anesthesia (64).

Proposed mechanism is that volatile anesthetics may suppress the activity of natural killer cells (65). In contrast, it has been reported that propofol did not suppress the natural killer activity (66). Propofol may also inhibit matrix metalloproteinases that are the key enzyme involved in breakdown of basement membrane, thus promoting tumor spread (67).

These mechanisms need future in vivo investigations, above all in the specific context of esophagectomy.

\section{Fluids and hemodynamic}

Surgical patients are particularly vulnerable to fluid overload; this is partially explained by the damage to the endothelial glycocalyx during surgery, justifying a more cautious approach to fluid administration $(68,69)$. Therefore, it is necessary to monitor the patient's fluid status and balance during the entire perioperative phase.

Fluid administration during anesthesia for esophageal surgery entails some complex aspects that need to be considered. This is because the surgery is a hybrid procedure: it is a gastroenterological procedure (often requiring large amounts of fluid) done in the context of the thorax (where fluids should be restricted) (70).

Depending on the specific surgical program, the patient's position (supine, lateral decubitus or prone) and the type of surgery (with or without a thoracotomy), two principal aspects need to be taken into account. First, we know that an intraoperative fluid volume $>4$ litres and higher fluid balances on post-operative day 1 are independent risks 


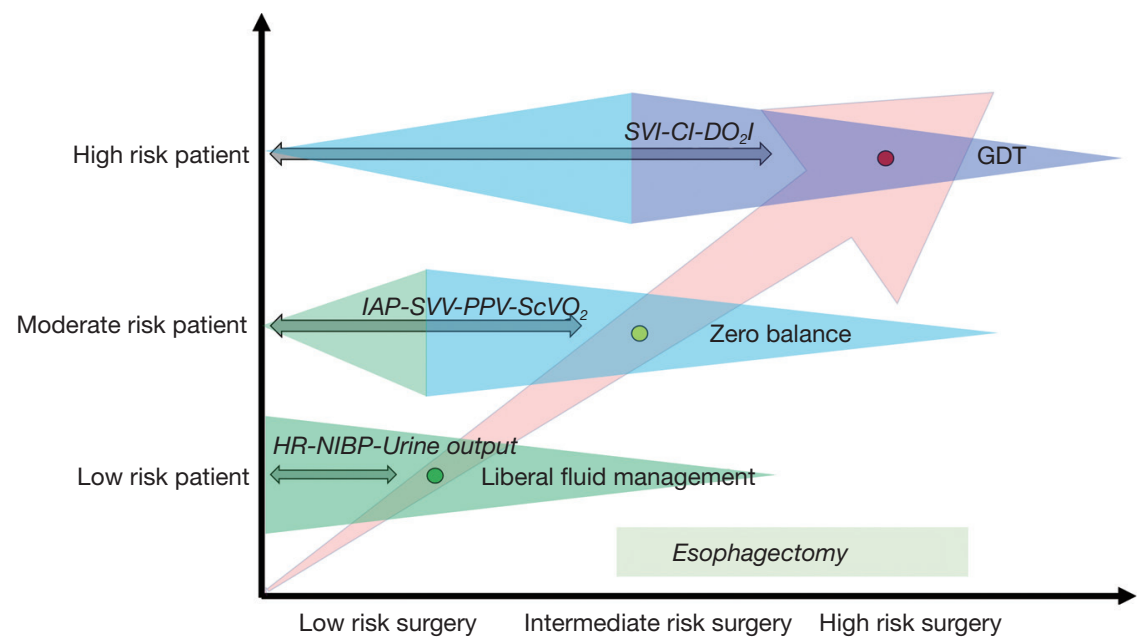

Figure 5 Peri-operative fluid and hemodynamic management for esophagectomy. Fluid strategy and hemodynamic approach consider the patient's anesthesiological peri-operative risk and the risk of surgery itself. For low-risk patients undergoing low risk surgery, standard monitoring and a liberal fluid strategy (green triangles) are considered a valuable option. Esophagectomy should be considered an intermediate-high risk surgery. Consequently, "zero balance" (light blue triangles) or GDT (blue triangles) approach are the proposed options: the former should be considered if the patient is at low-intermediate risk, the latter when a high-risk patient will face to esophagectomy. Hemodynamic monitoring is also included in the figure: patient at low-intermediate risk would benefit from mini-invasive approach, high-risk patients need more invasive tools. HR, heart rate; NIBP, non-invasive arterial blood pressure; IAP, invasive arterial blood pressure; SVV, stroke volume variation; PPV, pulse pressure variation; $\mathrm{ScVO}_{2}$, central venous oxygen saturation; SVI, stroke volume index; $\mathrm{CI}$, cardiac index; $\mathrm{DO}_{2} \mathrm{I}$, indexed oxygen delivery; GDT, goal directed fluid therapy.

factors for PPCs, with a $16 \%$ increase in the risk of postoperative symptoms for each additional litre and a $32 \%$ increase in the probability of PPCs after esophagectomy (71-73). Second, the restrictive fluid approach should not be translated as tout court in this type of surgery. Hypovolemia, in fact, exposes patients to the risk of renal failure after surgery with an incidence of about $6-24 \%(74,75)$.

From the literature, we know that anesthesiologists interpret the distinct approaches to fluid administration (labelled as "liberal" or "restrictive", for example) very differently, with the range of median crystalloid volumes administered being very wide, and scientific evidencebased RCTs addressing this type of surgery are, at present, lacking $(75,76)$. To make matters worse, in the open thorax approach, the dynamic indices (SPV, PPV and SVV) may be inaccurate to guide fluid therapy (77). The anesthesiologist is advised to rely on close observation of ongoing fluid losses (in/out fluid balance) and the maintenance of normal vital signs. We recommend Standard American Society of Anesthesiologists (ASA) monitoring plus invasive arterial pressure monitoring for all esophagectomies for the abovementioned reasons. Physiological reasons strongly support the conservative fluid strategy: the so called "zero-balance" approach (78).

Fluids are sometimes used improperly to counteract anesthesia-induced hypotension. In this case, the use of norepinephrine is justified and does not carry any risk (79).

Patients only need fluids if they are losing them, for example, through perspiratio insensibilis, blood loss or urine excretion. Therefore, the main general strategies of administering fluids to the patients during surgery, i.e., both restrictive and liberal approaches, seem contraindicated during esophagectomy.

In contrast, zero-fluid balance in low-risk patients, or goal-directed therapy (GDT) with less invasive devices in high-risk patients, seem to be the preferred modalities of fluid infusion (Figure 5) (80). GDT aims at optimizing the perfusion of organs, enhancing oxygen delivery to supranormal values $\left(\mathrm{DOI}_{2}>600 \mathrm{~mL} / \mathrm{min} / \mathrm{m}^{2}\right)$.

Evidence demonstrated that "perspiratio insensibilis" is about $1 \mathrm{~mL} / \mathrm{kg} / \mathrm{h}$ during open abdominal surgery (81); in addition, thanks to mini-invasive procedures, blood loss during esophagectomy is scarce. As a consequence, maintenance infusion rate of $1-3 \mathrm{~mL} / \mathrm{kg} / \mathrm{h}$ of balanced fluid solutions seems to be a reasonable approach to obtain a "zero balance" at the end of surgery. 
A large volume of evidence exists showing this strategy to be superior to the other approaches in high-risk surgery $(82,83)$. Many studies, including metanalyses, demonstrate lower post-operative complications, shorter lengths of hospital stay and better survival (84). Some reports also specifically highlight the advantage of GDT for esophagectomy, revealing better post-operative outcomes $(84,85)$.

\section{Depth of anesthesia monitoring}

It is important to administer as much anesthetic as required to the patient, avoiding both under and over dosage. There are a number of different machines on the market for monitoring depth of anesthesia, but the majority of published data have been obtained through bispectral index (BIS) technology, which processes the EEG signal and provides a value reflecting the depth of anesthetic plane, especially during intravenous anesthesia (86).

A recent meta-analysis showed that BIS might have a protective effect against post-operative delirium (POD) on day 1 and against post-operative cognitive dysfunction (POCD) at 12 weeks after surgery (87). Enhanced recovery after surgery (ERAS) programmes strongly recommend BIS use during esophagectomy (88). However, Yang and colleagues in the specific context of esophagectomy found that BIS-guided individualized anesthesia did not reduce inadequate emergence or POD (89). We suggest titrating anesthesia depth with the help of a monitor rather than going blind. In addition, whatever the monitoring system, it is necessary to consider its advantages as well as its limitations.

\section{Temperature}

Core body temperature (central temperature as set by the hypothalamus) should be kept $>36^{\circ} \mathrm{C}$ throughout the perioperative phase (90). Some evidence suggests prewarming patients prior to entering the operating room and ensuring normothermia during surgery by heating intravenous fluids or by applying forced-air blankets, warming mattresses or circulating-water garment systems (91). Temperature monitoring is recommended using adequate instrumentation, such as a urinary catheter with thermal probe, which are readily available in the majority of hospitals. The achievement of normothermia, a perioperative goal, has also been shown to reduce postoperative complications after esophagectomy (92).

\section{Blood products transfusion}

Intraoperative blood losses are scarce with the new mini-invasive techniques. So, transfusions are rarely needed nowadays (93). In addition, various studies have demonstrated that perioperative red blood cell (RBC) transfusions are associated with more postoperative complications and a higher risk of death after esophagectomy $(71,94,95)$. RBC administration is only advisable for $\mathrm{Hb}$ levels $<7 \mathrm{~g} / \mathrm{dL}$ in the absence of cardiac disease and with normal organ perfusion parameters (lactate levels within normal range, adequate urine output, normal $\mathrm{S}_{\mathrm{c}} \mathrm{VO}_{2}$ and hemodynamic stability). On the contrary, a higher threshold level should be considered $(\mathrm{Hb}<8-9 \mathrm{~g} / \mathrm{dL}$ ) in the case of any sign of inadequate organ perfusion or known cardiac disease. It is rarely necessary to give RBC for $\mathrm{Hb}>10 \mathrm{~g} / \mathrm{dL}$.

\section{Post-operative management}

\section{High dependency unit (HDU)/ICU admission}

Extubation in the operating room after uneventful surgery is a feasible and safe option if vital parameters are within normal values, especially if oxygenation, hemodynamic stability, normothermia, pain control and NMB reversal are obtained at the end of surgery (11).

Whether the patient needs HDU (or advanced care unit) or ICU admission is a choice that every surgical centre should plan for. The decision should be based on the local resources available in terms of staff, technology and finances (96). As a general rule, low risk patients (ASA 1-2) could be discharged from the OR onto a HDU if available. Higher risk patients (ASA 3) are more likely suitable for ICU admission, ASA 4 patients or those unstable after surgery must enter the ICU for post-surgery stabilization and optimization.

\section{Analgesia}

Effective pain management after esophagectomy is essential for patient comfort, early recovery, low surgical morbidity and a short hospitalization period. The pain experienced after thoracotomy has been described as being one of the worst (97). Perioperative pain management is a prerogative for anesthesiologists. Depending on the type of surgery adopted (i.e., open versus minimally invasive), different approaches may be selected. Epidural catheter analgesia (EDA) is probably the best tool available for the control of post-operative pain, especially in the case of thoracotomy (98). In fact, ERAS protocols strongly recommend the use of EDA as the first-choice modality (88). Anesthetic in the epidural space seems to increase visceral blood flow, thus reducing ischemic events in the 
neoesophagus (99). In addition, some evidence highlights better post-operative pulmonary function, especially in chronic obstructive pulmonary disease (COPD) patients undergoing major abdominal surgery (100). EDA seems to be protective against chronic post-thoracotomy pain even if strong evidence supporting this is missing (101).

Moreover, patients with an epidural catheter require special attention: hemodynamic parameters should be frequently checked to intercept possible hypotension, neurological examination should evaluate the sensitivity and mobility of the legs (to rule out epidural hematoma, for example), and the insertion site should be checked to confirm that it is free from infection. Considering these aspects, patients in EDA need more staff care and resources, such as a 24-h acute pain service (102). Considering that surgical techniques are less invasive nowadays, other analgesic regimens may be applied more easily.

Paravertebral blocks (PVB) and erector spine block (ESP) are two valid options $(103,104)$. These approaches are less invasive and less risky than EDA and could be the right choice in a multimodal approach. They give less hypotension than EDA, leading to less fluid load and need for vasopressors. Sometimes a combination of spinal opioid with PVB or ESP is used.

These aspects improve early post-operative mobilization of the patients. These techniques could also be useful in cases of patients under peri-operative anticoagulation (103-105).

An ongoing trial (PEPMEN trial) is recruiting patients undergoing MIE comparing the postoperative quality of recovery between paravertebral catheter versus thoracic epidural analgesia (106).

Transversus abdominis plane (TAP) block represents another option in the post-operative pain treatment armamentarium (107).

Intravenous analgesia with or without opioids probably continues to be the most used type of analgesic regimen as a result of its easy application and its usually sufficient pain control in conjunction with its low risk for postoperative adverse events. Acetaminophen, non-steroidal ant inflammatory drugs (NSAIDs) and opioids are largely used (101).

Postoperative scheduled acetaminophen has demonstrated to reduce opioid use without drawbacks on post-operative pain control (108). Its efficacy, with the easiness of administration, make acetaminophen a valid analgesic option within multimodal analgesia.

Ketorolac and other NSAIDs have raised concern about their possible role in the development of anastomotic leakage (109).

Dexmedetomidine and sufentanil patient-controlled analgesia (PCA) was demonstrated to reduce inflammation, improve post-operative pain relief, and to reduce delirium after MIE in a recent randomized controlled trial. However, sample size was low, and further research is needed (110).

The role of adjuncts, such as gabapentinoids, magnesium, lignocaine and ketamine, is not well established (11).

In summary, pain control must be tailored for every patient, considering the comorbidities, the type of surgery (open versus laparoscopic surgery) and the resources available in each specific centre, respecting the safety and efficacy of the treatment itself.

\section{Post-operative respiratory support}

Large RCTs are still required to determine the potential benefits of preventive non-invasive ventilation [C-PAP/ pressure support or high flow nasal cannula (HFNC)] after esophagectomy. Indeed, concern for neo-conduit dehiscence or increased risk of aspiration (due to the loss of the lower esophageal sphincter combined with pyloric spasm) has limited the adoption of this kind of ventilation as a preventive treatment following extubation (111). However, a retrospective study has demonstrated that non-invasive positive pressure ventilation (NIPPV) is an effective option for the treatment of ARDS/acute lung injury (ALI) after esophagectomy $(112,113)$. HFNC was also found to improve hypoxemia in patients after esophagectomy, increase the flow of sputum and reduce the incidence of PPC and anastomotic leakage compared with conventional oxygen therapy via a standard face mask (114). It is, therefore, reasonable to implement perioperative respiratory care (in particular, chest physiotherapy) with HFNC for the first 48-72 hours after extubation, but further and stronger evidence is still required.

\section{Conclusions}

Esophagectomy remains a high-risk form of surgery. Patients undergoing esophagectomy should only be referred to high volume centres as these offer better post-operative outcomes.

Anesthesiologists, nowadays, are the leading medical figures in charge of perioperative care, including that for esophagectomy. They follow patients from the time of diagnosis through to the post-operative phase. Preoperative anesthesiological evaluation is mandatory in order to stratify and optimize any medical condition. 
During surgery, protective ventilation and judicious fluid management are the cornerstones of intraoperative "protective anesthesia". Post-operative pain management, respiratory support and fluid balance are three of the most crucial issues in which anesthesiologists must invest in order to offer the best evidence-based treatments presently available for the care of these patients. In the future, AI is likely to provide new ways of helping clinicians optimize the perioperative path for esophagectomy. Nonetheless, much work still needs to be done to improve the surgical outcomes for our patients (115)!

\section{Acknowledgments}

The authors would like to thanks to Dr. Stephanie Parsley for English professional editing.

Funding: None.

\section{Footnote}

Reporting Checklist: The authors have completed the Narrative Review reporting checklist. Available at https:// dx.doi.org/10.21037/jtd-21-940

Peer Review File: Available at https://dx.doi.org/10.21037/ jtd-21-940

Conflicts of Interest: All authors have completed the ICMJE uniform disclosure form (available at https://dx.doi. org/10.21037/jtd-21-940). The authors have no conflicts of interest to declare.

Ethical Statement: The authors are accountable for all aspects of the work in ensuring that questions related to the accuracy or integrity of any part of the work are appropriately investigated and resolved.

Open Access Statement: This is an Open Access article distributed in accordance with the Creative Commons Attribution-NonCommercial-NoDerivs 4.0 International License (CC BY-NC-ND 4.0), which permits the noncommercial replication and distribution of the article with the strict proviso that no changes or edits are made and the original work is properly cited (including links to both the formal publication through the relevant DOI and the license). See: https://creativecommons.org/licenses/by-nc-nd/4.0/.

\section{References}

1. Takahashi C, Shridhar R, Huston J, et al. Esophagectomy from then to now. J Gastrointest Oncol 2018;9:903-9.

2. Available online: https://gco.iarc.fr

3. Jemal A, Bray F, Center MM, et al. Global cancer statistics. CA Cancer J Clin 2011;61:69-90.

4. Domper Arnal MJ, Ferrández Arenas Á, Lanas Arbeloa Á. Esophageal cancer: Risk factors, screening and endoscopic treatment in Western and Eastern countries. World J Gastroenterol 2015;21:7933-43.

5. Ovrebo KK, Lie SA, Laerum OD, et al. Long-term survival from adenocarcinoma of the esophagus after transthoracic and transhiatal esophagectomy. World J Surg Oncol 2012;10:130.

6. Dimick JB, Pronovost PJ, Cowan JA, et al. Surgical volume and quality of care for esophageal resection: do highvolume hospitals have fewer complications? Ann Thorac Surg 2003;75:337-41.

7. Markar S, Gronnier C, Duhamel A, et al. Pattern of Postoperative Mortality After Esophageal Cancer Resection According to Center Volume: Results from a Large European Multicenter Study. Ann Surg Oncol 2015;22:2615-23.

8. Harrison S, Tangel V, Wu X, et al. Are minimum volume standards appropriate for lung and esophageal surgery? J Thorac Cardiovasc Surg 2018;155:2683-2694.e1.

9. BUßMEYER F, Kneifel F, Eichelmann AK, et al. Effects of therapy modifications during the last decade on the outcome of patients undergoing esophagectomy for esophageal cancer. Minerva Surg 2021;76:235-44.

10. Stephens MR, Lewis WG, Brewster AE, et al. Multidisciplinary team management is associated with improved outcomes after surgery for esophageal cancer. Dis Esophagus 2006;19:164-71.

11. Carney A, Dickinson M. Anesthesia for esophagectomy. Anesthesiol Clin 2015;33:143-63.

12. Della Rocca G, Vetrugno L, Coccia C, et al. Preoperative Evaluation of Patients Undergoing Lung Resection Surgery: Defining the Role of the Anesthesiologist on a Multidisciplinary Team. J Cardiothorac Vasc Anesth 2016;30:530-8.

13. Kakegawa T, Fujita H. A history of esophageal surgery in the twentieth century. Gen Thorac Cardiovasc Surg 2009;57:55-63.

14. McKeown KC. Total three-stage oesophagectomy for cancer of the oesophagus. Br J Surg 1976;63:259-62. 
15. Bartels K, Fiegel M, Stevens Q, et al. Approaches to perioperative care for esophagectomy. J Cardiothorac Vasc Anesth 2015;29:472-80.

16. Papenfuss WA, Kukar M, Attwood K, et al. Transhiatal versus transthoracic esophagectomy for esophageal cancer: a 2005-2011 NSQIP comparison of modern multicenter results. J Surg Oncol 2014;110:298-301.

17. van Rijswijk AS, Hagens ERC, van der Peet DL, et al. Differences in Esophageal Cancer Surgery in Terms of Surgical Approach and Extent of Lymphadenectomy: Findings of an International Survey. Ann Surg Oncol 2019;26:2063-72.

18. Straatman J, van der Wielen N, Cuesta MA, et al. Minimally Invasive Versus Open Esophageal Resection: Three-year Follow-up of the Previously Reported Randomized Controlled Trial: the TIME Trial. Ann Surg 2017;266:232-6.

19. Tsunoda S, Obama K, Hisamori S, et al. Lower Incidence of Postoperative Pulmonary Complications Following Robot-Assisted Minimally Invasive Esophagectomy for Esophageal Cancer: Propensity Score-Matched Comparison to Conventional Minimally Invasive Esophagectomy. Ann Surg Oncol 2021;28:639-47.

20. Claassen L, van Workum F, Rosman C. Learning curve and postoperative outcomes of minimally invasive esophagectomy. J Thorac Dis 2019;11:S777-85.

21. Kingma BF, de Maat MFG, van der Horst S, et al. Robotassisted minimally invasive esophagectomy (RAMIE) improves perioperative outcomes: a review. J Thorac Dis 2019;11:S735-42.

22. Aisu Y, Hori T, Kato S, et al. Brachial plexus paralysis after thoracoscopic esophagectomy for esophageal cancer in the prone position: A thought-provoking case report of an unexpected complication. Int J Surg Case Rep 2019;55:11-4.

23. Kristensen SD, Knuuti J, Saraste A, et al. 2014 ESC/ ESA Guidelines on non-cardiac surgery: cardiovascular assessment and management: The Joint Task Force on non-cardiac surgery: cardiovascular assessment and management of the European Society of Cardiology (ESC) and the European Society of Anaesthesiology (ESA). Eur Heart J 2014;35:2383-431.

24. Low DE, Kuppusamy MK, Alderson D, et al. Benchmarking Complications Associated with Esophagectomy. Ann Surg 2019;269:291-8.

25. Sivakumar J, Sivakumar H, Read M, et al. The Role of Cardiopulmonary Exercise Testing as a Risk Assessment Tool in Patients Undergoing Oesophagectomy: A
Systematic Review and Meta-analysis. Ann Surg Oncol 2020;27:3783-96.

26. Biccard BM. Relationship between the inability to climb two flights of stairs and outcome after major non-cardiac surgery: implications for the pre-operative assessment of functional capacity. Anaesthesia 2005;60:588-93.

27. Mauermann E, De Hert S, Dell-Kuster S, et al. Reevaluation of peri-operative cardiac risk (the MET REPAIR study): Study protocol of a prospective, multicentre cohort study sponsored by the European Society of Anaesthesiology. Eur J Anaesthesiol 2017;34:709-12.

28. Hou JL, Gao K, Li M, et al. Increased N-terminal probrain natriuretic peptide level predicts atrial fibrillation after surgery for esophageal carcinoma. World J Gastroenterol 2008;14:2582-5.

29. Vetrugno L, Orso D, Matellon C, et al. The Possible Use of Preoperative Natriuretic Peptides for Discriminating Low Versus Moderate-High Surgical Risk Patient. Semin Cardiothorac Vasc Anesth 2018;22:395-402.

30. Levett DZH, Jack S, Swart M, et al. Perioperative cardiopulmonary exercise testing (CPET): consensus clinical guidelines on indications, organization, conduct, and physiological interpretation. Br J Anaesth 2018;120:484-500.

31. Nagatsuka Y, Sugimura K, Miyata H, et al. Predictive value of preoperative echocardiographic assessment for postoperative atrial fibrillation after esophagectomy for esophageal cancer. Esophagus 2021;18:496-503.

32. Raman T, Roistacher N, Liu J, et al. Preoperative left atrial dysfunction and risk of postoperative atrial fibrillation complicating thoracic surgery. J Thorac Cardiovasc Surg 2012;143:482-7.

33. Lund M, Tsai JA, Nilsson M, et al. Effects of neoadjuvant chemo or chemoradiotherapy for oesophageal cancer on perioperative haemodynamics: A prospective cohort study within a randomised clinical trial. Eur J Anaesthesiol 2016;33:653-61.

34. Dettling DS, van der Schaaf M, Blom RL, et al. Feasibility and effectiveness of pre-operative inspiratory muscle training in patients undergoing oesophagectomy: a pilot study. Physiother Res Int 2013;18:16-26.

35. Allen S, Brown V, Prabhu P, et al. A randomised controlled trial to assess whether prehabilitation improves fitness in patients undergoing neoadjuvant treatment prior to oesophagogastric cancer surgery: study protocol. BMJ Open 2018;8:e023190.

36. Davies SJ, West MA, Rahman SA, et al. Oesophageal 
cancer: The effect of early nutrition support on clinical outcomes. Clin Nutr ESPEN 2021;42:117-23.

37. Veelo DP, Geerts BF. Anaesthesia during oesophagectomy. J Thorac Dis 2017;9:S705-12.

38. Arends J, Baracos V, Bertz H, et al. ESPEN expert group recommendations for action against cancer-related malnutrition. Clin Nutr 2017;36:1187-96.

39. Rasmussen HH, Holst M, Kondrup J. Measuring nutritional risk in hospitals. Clin Epidemiol 2010;2:209-16.

40. Kwon JH, Park J, Lee SH, et al. Pre-operative anaemia and myocardial injury after noncardiac surgery: A retrospective study. Eur J Anaesthesiol 2021;38:582-90.

41. Richards T, Baikady RR, Clevenger B, et al. Preoperative intravenous iron for anaemia in elective major open abdominal surgery: the PREVENTT RCT. Health Technol Assess 2021;25:1-58.

42. Ashok A, Niyogi D, Ranganathan P, et al. The enhanced recovery after surgery (ERAS) protocol to promote recovery following esophageal cancer resection. Surg Today 2020;50:323-34.

43. Ferreira V, Agnihotram RV, Bergdahl A, et al. Maximizing patient adherence to prehabilitation: what do the patients say? Support Care Cancer 2018;26:2717-23.

44. Piraux E, Caty G, Reychler G, et al. Feasibility and Preliminary Effectiveness of a Tele-Prehabilitation Program in Esophagogastric Cancer Patients. J Clin Med 2020;9:2176.

45. Frerk C, Mitchell VS, McNarry AF, et al. Difficult Airway Society 2015 guidelines for management of unanticipated difficult intubation in adults. Br J Anaesth 2015;115:827-48.

46. Langiano N, Fiorelli S, Deana C, et al. Airway management in anesthesia for thoracic surgery: a "real life" observational study. J Thorac Dis 2019;11:3257-69.

47. Larsen S, Holm JH, Sauer TN, et al. A Cost-Effectiveness Analysis Comparing the VivaSight Double-Lumen Tube and a Conventional Double-Lumen Tube in Adult Patients Undergoing Thoracic Surgery Involving One-Lung Ventilation. Pharmacoecon Open 2020;4:159-69.

48. Merli G, Guarino A, Della Rocca G, et al. Recommendations for airway control and difficult airway management in thoracic anesthesia and lung separation procedures. Minerva Anestesiol 2009;75:59-78; 79-96.

49. Deng QW, Tan WC, Zhao BC, et al. Intraoperative ventilation strategies to prevent postoperative pulmonary complications: a network meta-analysis of randomised controlled trials. Br J Anaesth 2020;124:324-35.

50. Güldner A, Kiss T, Serpa Neto A, et al. Intraoperative protective mechanical ventilation for prevention of postoperative pulmonary complications: a comprehensive review of the role of tidal volume, positive end-expiratory pressure, and lung recruitment maneuvers. Anesthesiology 2015;123:692-713.

51. Reichert M, Schistek M, Uhle F, et al. Ivor Lewis esophagectomy patients are particularly vulnerable to respiratory impairment - a comparison to major lung resection. Sci Rep 2019;9:11856.

52. Howells P, Thickett D, Knox C, et al. The impact of the acute respiratory distress syndrome on outcome after oesophagectomy. Br J Anaesth 2016;117:375-81.

53. Serpa Neto A, Hemmes SN, Barbas CS, et al. Protective versus Conventional Ventilation for Surgery: A Systematic Review and Individual Patient Data Meta-analysis. Anesthesiology 2015;123:66-78.

54. Shen $\mathrm{Y}$, Zhong $\mathrm{M}, \mathrm{Wu} \mathrm{W}$, et al. The impact of tidal volume on pulmonary complications following minimally invasive esophagectomy: a randomized and controlled study. J Thorac Cardiovasc Surg 2013;146:1267-73; discussion 1273-4.

55. Young CC, Harris EM, Vacchiano C, et al. Lungprotective ventilation for the surgical patient: international expert panel-based consensus recommendations. $\mathrm{Br} \mathrm{J}$ Anaesth 2019;123:898-913.

56. Şentürk M, Slinger P, Cohen E. Intraoperative mechanical ventilation strategies for one-lung ventilation. Best Pract Res Clin Anaesthesiol 2015;29:357-69.

57. PROVE Network Investigators for the Clinical Trial Network of the European Society of Anaesthesiology; Hemmes SN, Gama de Abreu M, et al. High versus low positive end-expiratory pressure during general anaesthesia for open abdominal surgery (PROVHILO trial): a multicentre randomised controlled trial. Lancet 2014;384:495-503.

58. Battaglini D, Ball L, Wittenstein J, et al. PEEP in thoracic anesthesia: pros and cons. Minerva Anestesiol 2021;87:223-9.

59. Fernandez-Bustamante A, Sprung J, Parker RA, et al. Individualized PEEP to optimise respiratory mechanics during abdominal surgery: a pilot randomised controlled trial. Br J Anaesth 2020;125:383-92.

60. Ferrando C, Soro M, Unzueta C, et al. Individualised perioperative open-lung approach versus standard protective ventilation in abdominal surgery (iPROVE): a randomised controlled trial. Lancet Respir Med 2018;6:193-203.

61. Choi YS, Shim JK, Na S, et al. Pressure-controlled versus 
volume-controlled ventilation during one-lung ventilation in the prone position for robot-assisted esophagectomy. Surg Endosc 2009;23:2286-91.

62. Campos JH, Feider A. Hypoxia During One-Lung Ventilation-A Review and Update. J Cardiothorac Vasc Anesth 2018;32:2330-8.

63. Chang CY, Wu MY, Chien YJ, et al. Anesthesia and Longterm Oncological Outcomes: A Systematic Review and Meta-analysis. Anesth Analg 2021;132:623-34.

64. Jun IJ, Jo JY, Kim JI, et al. Impact of anesthetic agents on overall and recurrence-free survival in patients undergoing esophageal cancer surgery: A retrospective observational study. Sci Rep 2017;7:14020.

65. Stollings LM, Jia LJ, Tang P, et al. Immune Modulation by Volatile Anesthetics. Anesthesiology 2016;125:399-411.

66. Melamed R, Bar-Yosef S, Shakhar G, et al. Suppression of natural killer cell activity and promotion of tumor metastasis by ketamine, thiopental, and halothane, but not by propofol: mediating mechanisms and prophylactic measures. Anesth Analg 2003;97:1331-9.

67. Xu YB, Du QH, Zhang MY, et al. Propofol suppresses proliferation, invasion and angiogenesis by downregulating ERK-VEGF/MMP-9 signaling in Eca-109 esophageal squamous cell carcinoma cells. Eur Rev Med Pharmacol Sci 2013;17:2486-94.

68. Della Rocca G, Vetrugno L, Tripi G, et al. Liberal or restricted fluid administration: are we ready for a proposal of a restricted intraoperative approach? BMC Anesthesiol 2014;14:62.

69. Doherty M, Buggy DJ. Intraoperative fluids: how much is too much? Br J Anaesth 2012;109:69-79.

70. Bonavina L, Asti E, Sironi A, et al. Hybrid and total minimally invasive esophagectomy: how I do it. J Thorac Dis 2017;9:S761-72.

71. Deana C, Vetrugno L, Stefani F, et al. Postoperative complications after minimally invasive esophagectomy in the prone position: any anesthesia-related factor? Tumori 2020. [Epub ahead of print]. doi: 10.1177/0300891620979358.

72. D'Souza RS, Sims CR 3rd, Andrijasevic N, et al. Pulmonary Complications in Esophagectomy Based on Intraoperative Fluid Rate: A Single-Center Study. J Cardiothorac Vasc Anesth 2021;35:2952-60.

73. Wei S, Tian J, Song X, et al. Association of perioperative fluid balance and adverse surgical outcomes in esophageal cancer and esophagogastric junction cancer. Ann Thorac Surg 2008;86:266-72.

74. Myles PS, Bellomo R, Corcoran T, et al. Restrictive versus
Liberal Fluid Therapy for Major Abdominal Surgery. N Engl J Med 2018;378:2263-74.

75. Konda P, Ai D, Guerra CE, et al. Identification of Risk Factors Associated With Postoperative Acute Kidney Injury After Esophagectomy for Esophageal Cancer. J Cardiothorac Vasc Anesth 2017;31:474-81.

76. Buise MP. Proper volume management during anesthesia for esophageal resection. J Thorac Dis 2019;11:S702-6.

77. Marik PE, Lemson J. Fluid responsiveness: an evolution of our understanding. Br J Anaesth 2014;112:617-20.

78. Perez Nieto OR, Wong A, Lopez Fermin J, et al. Aiming for zero fluid accumulation: First, do no harm. Anaesthesiol Intensive Ther 2021;53:162-78.

79. Walsh KJ, Zhang H, Tan KS, et al. Use of vasopressors during esophagectomy is not associated with increased risk of anastomotic leak. Dis Esophagus 2021;34:doaa090.

80. Klevebro F, Boshier PR, Low DE. Application of standardized hemodynamic protocols within enhanced recovery after surgery programs to improve outcomes associated with anastomotic leak and conduit necrosis in patients undergoing esophagectomy. J Thorac Dis 2019;11:S692-701.

81. Lamke LO, Nilsson GE, Reithner HL. Water loss by evaporation from the abdominal cavity during surgery. Acta Chir Scand 1977;143:279-84.

82. Fellahi JL, Futier E, Vaisse C, et al. Perioperative hemodynamic optimization: from guidelines to implementation-an experts' opinion paper. Ann Intensive Care 2021;11:58.

83. Mukai A, Suehiro K, Watanabe R, et al. Impact of intraoperative goal-directed fluid therapy on major morbidity and mortality after transthoracic oesophagectomy: a multicentre, randomised controlled trial. Br J Anaesth 2020;125:953-61.

84. Veelo DP, van Berge Henegouwen MI, Ouwehand KS, et al. Effect of goal-directed therapy on outcome after esophageal surgery: A quality improvement study. PLoS One 2017;12:e0172806.

85. Taniguchi H, Sasaki T, Fujita H, et al. Effects of goaldirected fluid therapy on enhanced postoperative recovery: An interventional comparative observational study with a historical control group on oesophagectomy combined with ERAS program. Clin Nutr ESPEN 2018;23:184-93.

86. Gao WW, He YH, Liu L, et al. BIS Monitoring on Intraoperative Awareness: A Meta-analysis. Curr Med Sci 2018;38:349-53.

87. Bocskai T, Kovács M, Szakács Z, et al. Is the bispectral index monitoring protective against postoperative 
cognitive decline? A systematic review with meta-analysis. PLoS One 2020;15:e0229018.

88. Low DE, Allum W, De Manzoni G, et al. Guidelines for Perioperative Care in Esophagectomy: Enhanced Recovery After Surgery (ERAS®) Society Recommendations. World J Surg 2019;43:299-330.

89. Yang Y, Song C, Song C, et al. Comparison of Bispectral Index-Guided Individualized Anesthesia with Standard General Anesthesia on Inadequate Emergence and Postoperative Delirium in Elderly Patients Undergoing Esophagectomy: A Retrospective Study at a Single Center. Med Sci Monit 2020;26:e925314.

90. Available online: https://www.siaarti.it/news?category_ $\mathrm{id}=30448$

91. Zhang Z, Xu M, Wu D, et al. Postoperative Myocardial Injury in Middle-Aged and Elderly Patients Following Curative Resection of Esophageal Cancer With Aggressive or Standard Body Temperature Management: A Randomized Controlled Trial. Anesth Analg 2019;129:352-9.

92. Yamasaki H, Tanaka K, Funai Y, et al. The impact of intraoperative hypothermia on early postoperative adverse events after radical esophagectomy for cancer: a retrospective cohort study. J Cardiothorac Vasc Anesth 2014;28:943-7.

93. Towe CW, Gulack BC, Kim S, et al. Restrictive Transfusion Practices After Esophagectomy Are Associated With Improved Outcome: A Review of the Society of Thoracic Surgeons General Thoracic Database. Ann Surg 2018;267:886-91.

94. Lee J, Chin JH, Kim JI, et al. Association between red blood cell transfusion and long-term mortality in patients with cancer of the esophagus after esophagectomy. Dis Esophagus 2018. doi: 10.1093/dote/dox123.

95. Kaufmann KB, Baar W, Glatz T, et al. Epidural analgesia and avoidance of blood transfusion are associated with reduced mortality in patients with postoperative pulmonary complications following thoracotomic esophagectomy: a retrospective cohort study of 335 patients. BMC Anesthesiol 2019;19:162.

96. O'Grady M, Firth R, Roberts R. Intensive care unit utilisation post-oesophagectomy. N Z Med J 2020;133:56-61.

97. Bayman EO, Curatolo M, Rahman S, et al. AAAPT Diagnostic Criteria for Acute Thoracic Surgery Pain. J Pain 2021;22:892-904.

98. Romero A, Garcia JE, Joshi GP. The state of the art in preventing postthoracotomy pain. Semin Thorac
Cardiovasc Surg 2013;25:116-24.

99. Lázár G, Kaszaki J, Abrahám S, et al. Thoracic epidural anesthesia improves the gastric microcirculation during experimental gastric tube formation. Surgery 2003;134:799-805.

100.van Lier F, van der Geest PJ, Hoeks SE, et al. Epidural analgesia is associated with improved health outcomes of surgical patients with chronic obstructive pulmonary disease. Anesthesiology 2011;115:315-21.

101. Visser E, Marsman M, van Rossum PSN, et al. Postoperative pain management after esophagectomy: a systematic review and meta-analysis. Dis Esophagus 2017;30:1-11.

102. Tilleul P, Aissou M, Bocquet F, et al. Cost-effectiveness analysis comparing epidural, patient-controlled intravenous morphine, and continuous wound infiltration for postoperative pain management after open abdominal surgery. Br J Anaesth 2012;108:998-1005.

103. Wang Q, Zhang G, Wei S, et al. Comparison of the Effects of Ultrasound-guided Erector Spinae Plane Block and Wound Infiltration on Perioperative Opioid Consumption and Postoperative Pain in Thoracotomy. J Coll Physicians Surg Pak 2019;29:1138-43.

104. Helms O, Mariano J, Hentz JG, et al. Intra-operative paravertebral block for postoperative analgesia in thoracotomy patients: a randomized, double-blind, placebo-controlled study. Eur J Cardiothorac Surg 2011;40:902-6.

105. Donohoe CL, Phillips AW, Flynn E, et al. Multimodal analgesia using intrathecal diamorphine, and paravertebral and rectus sheath catheters are as effective as thoracic epidural for analgesia post-open two-phase esophagectomy within an enhanced recovery program. Dis Esophagus 2018. doi: 10.1093/dote/doy006.

106. Kingma BF, Eshuis WJ, de Groot EM, et al. Paravertebral catheter versus EPidural analgesia in Minimally invasive Esophageal resectioN: a randomized controlled multicenter trial (PEPMEN trial). BMC Cancer 2020;20:142.

107.Levy G, Cordes MA, Farivar AS, et al. Transversus Abdominis Plane Block Improves Perioperative Outcome After Esophagectomy Versus Epidural. Ann Thorac Surg 2018;105:406-12.

108. Ohkura Y, Shindoh J, Ueno M, et al. A new postoperative pain management (intravenous acetaminophen: Acelio®) leads to enhanced recovery after esophagectomy: a propensity score-matched analysis. Surg Today 2018;48:502-9. 
109. Fjederholt KT, Okholm C, Svendsen LB, et al. Ketorolac and Other NSAIDs Increase the Risk of Anastomotic Leakage After Surgery for GEJ Cancers: a Cohort Study of 557 Patients. J Gastrointest Surg 2018;22:587-94.

110. Tang C, Hu Y, Zhang Z, et al. Dexmedetomidine with sufentanil in intravenous patient-controlled analgesia for relief from postoperative pain, inflammation and delirium after esophageal cancer surgery. Biosci Rep 2020;40:BSR20193410.

111. Michelet P, Blayac D, Jaber S. Case scenario: management of postesophagectomy respiratory failure with noninvasive ventilation. Anesthesiology 2010;113:454-61.

112. Yu KY, Zhao L, Chen Z, et al. Noninvasive positive pressure ventilation for the treatment of acute respiratory

Cite this article as: Deana C, Vetrugno L, Bignami E, Bassi F. Peri-operative approach to esophagectomy: a narrative review from the anesthesiological standpoint. J Thorac Dis 2021;13(10):6037-6051. doi: 10.21037/jtd-21-940 distress syndrome following esophagectomy for esophageal cancer: a clinical comparative study. J Thorac Dis 2013;5:777-82.

113. Michelet P, D'Journo XB, Seinaye F, et al. Non-invasive ventilation for treatment of postoperative respiratory failure after oesophagectomy. Br J Surg 2009;96:54-60.

114.Xia M, Li W, Yao J, et al. A postoperative comparison of high-flow nasal cannula therapy and conventional oxygen therapy for esophageal cancer patients. Ann Palliat Med 2021;10:2530-9.

115.Phillips AW, Kamarajah SK, Griffin SM. ASO Author Reflections: 30 Years of Esophagectomy. Ann Surg Oncol 2021;28:3023-4. 